\title{
Treatment of Pregnancy Complicated with Ovarian Tumor and its Effects on Pregnancy Outcome
}

\author{
JING GUO, SIRU CHEN ${ }^{1}$ AND YAN SHEN ${ }^{2 *}$
}

Department of Gynecology and Obstetrics, Huai'an Maternal and Child Health Care Center, ${ }^{1}$ The Department of Obstetrics and Gynecology, The Affiliated Huai'an Hospital of Xuzhou Medical University and The Second People's Hospital of Huai'an, Huai'an 223002, 'Department of Ultrasound, Lianshui County People's Hospital, Huai'an 223400, China

\section{Guo et al.: Treatment of Pregnancy Complicated with Ovarian Tumor}

This paper aims to observe and analyze treatment of pregnancy complicated with ovarian tumor and its effect on pregnancy outcome. A total of 160 patients with pregnancy complicated with ovarian tumor were enrolled in this study. They were treated in our hospital from February 2014 to February 2017. Statistics was made on pathological pattern of pregnancy complicated with ovarian tumor and diagnosis time and treatment, pregnancy outcomes and complications of different treatments were observed and analyzed. The risk of premature birth was higher in patients treated in late pregnancy than that of the patients treated in early and middle pregnancy and the difference was significant $(p<0.05)$. The incidence of complications in non-surgical patients was higher than that in the patients treated with surgery, with statistical significance $(\mathbf{p}<0.05)$. For patients with pregnancy complicated with ovarian tumor, the best surgical treatment time is early and middle pregnancy. Surgical treatment in late pregnancy will increase the risk of premature birth and non-surgical treatment will exacerbate complications during pregnancy.

Key words: Pregnancy complicated with ovarian tumor, surgical treatment, pregnancy outcome

According to relevant survey data, incidence of pregnancy with ovarian tumor is 1:81-1:2500 and incidence of malignant tumors is 1:8000-1:2000 or $\mathrm{so}^{[1]}$. With the development of social economy, people's living standards have also been improved, during which changes in the environment, life and increase of work pressure, changes in law of life and dietary structure cause varying degrees of impact on people's health. Therefore, group suffering from pregnancy with ovarian cancer shows an expanding trend. There are many factors for pregnancy with ovarian tumor and risk of complications of pregnancy, complicated with ovarian tumor is far higher than non-pregnancy. Thus, it has aroused widespread concern in the medical field. Pregnancy with ovarian tumor is a kind of obstetric and gynecological disease. With the continuous progress in modern medical prenatal examination, detection rate of pregnancy with ovarian tumor has been significantly enhanced. However, failure to implement reasonable and effective treatment program for ovarian tumor (fig. 1 ), will cause different degrees of damage to health of pregnant women on the one hand and lead to premature birth and even miscarriage on the other hand. Surgical resection of ovarian tumors by laparotomy or laparoscopic surgery may cause certain risk to the mother and the fetus, but implementation of nonsurgical treatment will easily lead to tumor rupture (fig. 2), tumor pedicle torsion (fig. 3) and other acute complications ${ }^{[2]}$, greatly affecting continued pregnancy and normal delivery. In this study, 160 patients with pregnancy complicated with ovarian tumor were selected as the subjects. Treatment of pregnancy with ovarian tumor and its effect on pregnancy outcome was retrospectively analyzed and explored. A total of 160 patients with pregnancy complicated with ovarian tumor were enrolled in this study. They were treated in our hospital from February 2014 to February 2017. All patients were diagnosed at admission with pregnancy complicated with ovarian tumor via B-type ultrasound or cesarean delivery. At the same time, the patients were entitled to a certain right to know and signed the relevant informed consent. The age of the patients was

*Address for correspondence

E-mail: zsg_yf@163.com 
between 24 and $37 \mathrm{y}$ old, with an average age of $(28.6 \pm 2.3)$ y. There were 106 cases of primipara, 54 cases of multipara and gravidity was ranged from 1 to 3 times, with an average of 2.4 times. There were 152 cases of singleton pregnancy and 8 cases of twin pregnancy. The diameter of the ovary mass was between $4 \mathrm{~cm}$ and $26 \mathrm{~cm}$, averaging $(8.6 \pm 0.7) \mathrm{cm}$. Cases of pregnancy diagnosis, early pregnancy diagnosis, middle pregnancy diagnosis and late pregnancy diagnosis numbered 24, 40, 22 and 74 respectively. For patients with a tumor diameter of $6 \mathrm{~cm}$ or less and patients in late pregnancy, non-surgical treatment program was taken, regular prenatal examination during pregnancy was performed and changes in tumor volume were closely monitored. For patients with a tumor diameter of more than $6 \mathrm{~cm}$, elective surgical treatment program was implemented and tumor was removed for middle pregnancy via laparoscopic surgery or laparotomy ${ }^{[3]}$. For patients with acute abdomen in early pregnancy, middle and late pregnancy, emergency laparoscopic surgery was performed ${ }^{[4]}$. All cases were treated with progesterone after surgery to prevent miscarriage. Observe pathological pattern of pregnancy complicated with ovarian tumor and diagnosis time and treatment, pregnancy outcomes and complications of different treatments and make statistics for comparison. The data were analyzed and processed by statistical package for the social sciences (SPSS) 21.0 statistical software. The counting data was expressed in (n, \%) and were tested by chi square. The measurement data was expressed in $(\overline{\mathrm{x}} \pm \mathrm{s})$ and tested by $\mathrm{t}$. Only when $\mathrm{p}<0.05$ is met, difference is considered to be statistically significant. As shown in Table 1 below, this study contains a total of 156 cases $(97.50 \%)$ of pregnancy with ovarian benign tumor and tumor like lesions, 4 cases $(2.50 \%)$ of malignant tumor. Wherein, pregnancy with ovarian benign tumor had 82 cases, accounting for $51.25 \%$, the most common was mature teratoma (fig. 4), $\mathrm{p}<0.05$; tumor like lesion had 74 cases, accounting for $46.25 \%$ and the common types include endometrioid cyst and corpus luteum cyst (fig. 5), $\mathrm{p}<0.05$. According to the statistics in Table 2 below, diagnosis time and treatment method of pregnancy complicated with ovarian tumor show that 24 cases, 40 cases, 22 cases and 74 cases were discovered in pre pregnancy, early pregnancy, middle pregnancy and late pregnancy respectively. There were 90 cases with non-surgical treatment program, 25 cases with elective surgery program, 26 cases with emergency surgery program and 19 cases giving up pregnancy. According to the statistics of
Table 3 below, comparison of pregnancy outcome of different treatments reveals that patients with surgical treatment and non-surgical treatment had no miscarriage; difference in pregnancy outcome of surgical treatment and non-surgical treatment was not statistically significant ( $>0.05)$; surgical treatment in late pregnancy has significantly higher risk of premature birth than treatment in early pregnancy and middle pregnancy. As shown in Table 3 below, there was no complication in the patients after surgery. Twelve patients had complications after non-surgical treatment, accounting for $13.33 \%$ (12/90). Incidence of complications in non-surgical patients was higher than that in patients with surgery. The difference was statistically significant $(p<0.05)$. In treatment of patients with pregnancy complicated with ovarian tumor, we not only need to treat tumor, but also carefully ensure that pregnancy outcome will not be affected. Pre pregnancy B-type ultrasound detection can timely detect ovarian tumors, so that active and effective measures can be taken for treatment, to prevent ovarian rupture and lower risk of torsion, miscarriage ${ }^{[5,6]}$. After pregnancy, if B-type ultrasound detection or cesarean delivery reveals ovarian tumor, targeted treatment should be provided. If the patient voluntarily requests to give up pregnancy, prior termination of pregnancy is needed. If practical circumstances are feasible, start laparoscopic resection ${ }^{[7,8]}$. When tumor diameter is less than $6 \mathrm{~cm}$, implement regular prenatal examination based on B-type ultrasound detection and reduce impact of the abdomen. If tumor is diagnosed in early pregnancy, wait until middle pregnancy and determine whether surgical resection is needed according to actual situation and practical needs of patients. If tumor diameter exceeds $6 \mathrm{~cm}$, provide laparotomy or laparoscopic surgical treatment and pay attention to complications ${ }^{[9,10]}$. During surgery, perform gently to avoid harm to the uterus. After surgery, patients should be routinely treated for miscarriage prevention. If ovarian tumor is found in middle pregnancy, due to low uterine sensitivity, try surgery immediately, which can receive safe and reliable curative effect. In the late pregnancy, once complication is found, immediately provide surgical treatment and deal with ovarian tumor after childbirth if the circumstances permit ${ }^{[11,12]}$. In late pregnancy, increased uterine volume and surgical operation difficulty will stimulate the uterus and cause premature birth. Therefore, best surgery time should be selected with reference to the patient's condition and situation of the fetus. The results of this study show that 
incidence of premature birth in patients treated in late pregnancy surgery is significantly higher than that in early pregnancy and middle pregnancy surgery. Surgery in late pregnancy can easily stimulate the uterus and induce premature birth. However, elective surgery in early pregnancy and surgery in middle pregnancy have little stimulation to the uterus, which are safe and reliable. Patients with surgical treatment had no acute complications after surgery, patients with non-surgical treatment had significantly higher incidence of acute complications than patients with surgical treatment, indicating that surgical treatment of pregnancy complicated with ovarian tumor can reduce incidence of acute complications. In summary, for pregnant women with ovarian tumor, the best surgical treatment time is early and middle pregnancy. Surgical treatment in late pregnancy will increase the risk of premature birth and non-surgical treatment will exacerbate complications during pregnancy. Therefore, treatment programs should be scientifically and rationally selected.

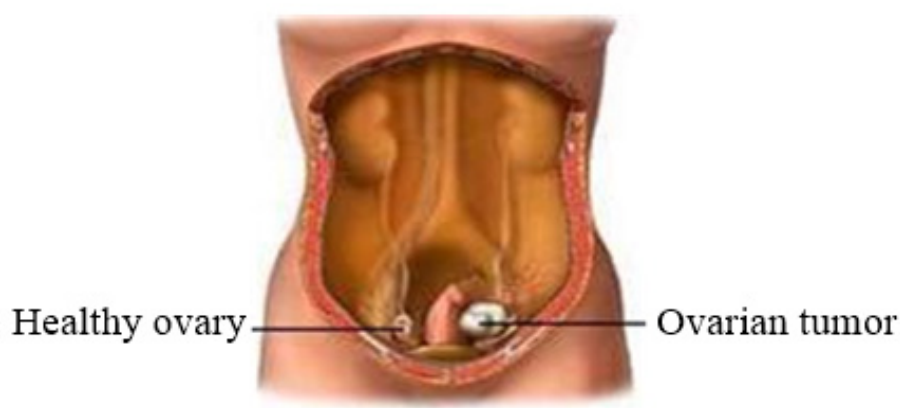

Fig. 1: Ovarian tumor

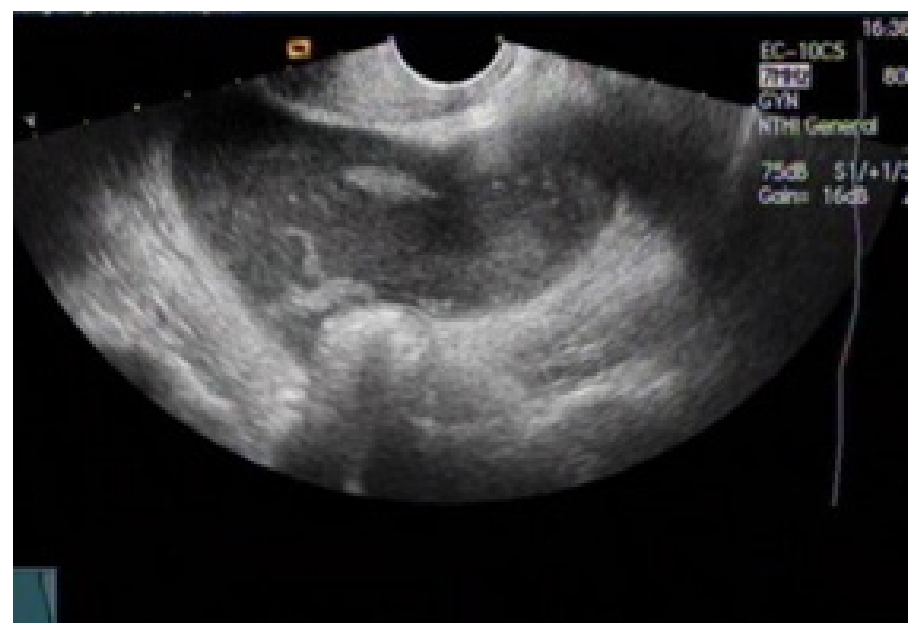

Fig. 2: Ovarian tumor rupture

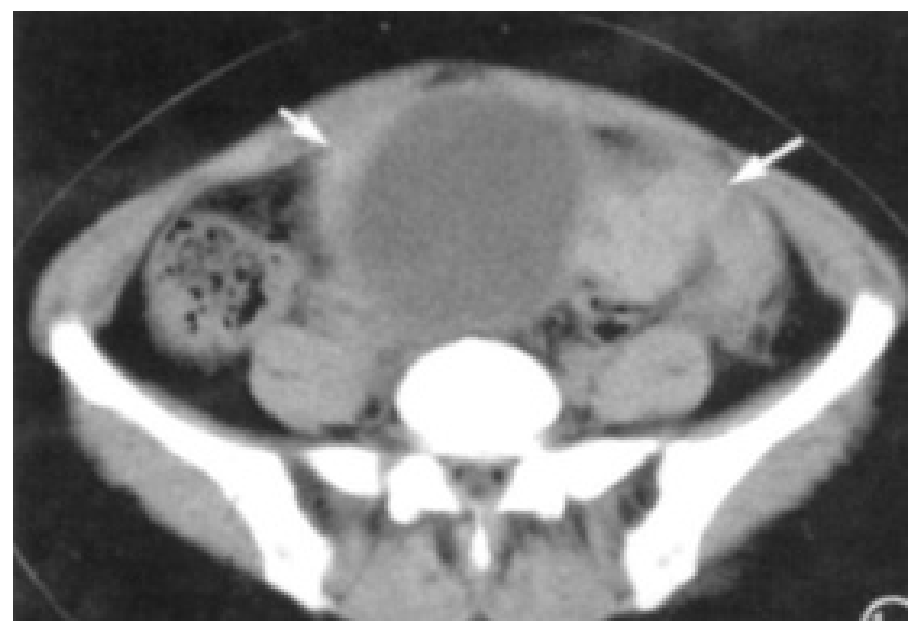

Fig. 3: Ovarian tumor torsion 
TABLE 1: PATHOLOGICAL TYPE OF PREGNANCY WITH OVARIAN TUMOR [n (\%)]

\begin{tabular}{|c|c|c|c|c|c|}
\hline Pathological type & Types & Left side & Right side & Bilateral & Total \\
\hline \multirow[t]{5}{*}{$\begin{array}{l}\text { Ovarian benign } \\
\text { tumor }(n=82)\end{array}$} & Mature cystic teratoma & 10 & 13 & 5 & 34.15 \\
\hline & Mucinous cystadenoma & 9 & 6 & 3 & 21.95 \\
\hline & Mucinous cystadenoma & 8 & 5 & 4 & 20.73 \\
\hline & Theca cell tumor & 6 & 2 & 3 & 13.41 \\
\hline & Fibroma & 4 & 3 & 1 & 9.76 \\
\hline \multirow[t]{3}{*}{$\begin{array}{l}\text { Ovarian tumor like } \\
\text { lesion }(n=74)\end{array}$} & Endometrioid cyst of ovary & 18 & 12 & 4 & 45.95 \\
\hline & Lutein or leuteivic cyst & 16 & 10 & 4 & 40.54 \\
\hline & Paramesonephric duct cyst & 3 & 5 & 2 & 13.51 \\
\hline \multirow[t]{4}{*}{$\begin{array}{l}\text { Ovarian malignant } \\
\text { tumor }(n=4)\end{array}$} & $\begin{array}{c}\text { Serous papillary } \\
\text { cystadenocarcinoma IC stage }\end{array}$ & - & - & 1 & 25.00 \\
\hline & $\begin{array}{c}\text { Borderline mucinous cystadenoma } \\
\text { of ovary }\end{array}$ & - & 1 & - & 25.00 \\
\hline & Immature teratoma & 1 & - & - & 25.00 \\
\hline & $\begin{array}{l}\text { Mucous cystoadenocarcinoma IC } \\
\text { stage }\end{array}$ & 1 & - & - & 25.00 \\
\hline Total & & 76 & 57 & 27 & 100.00 \\
\hline
\end{tabular}

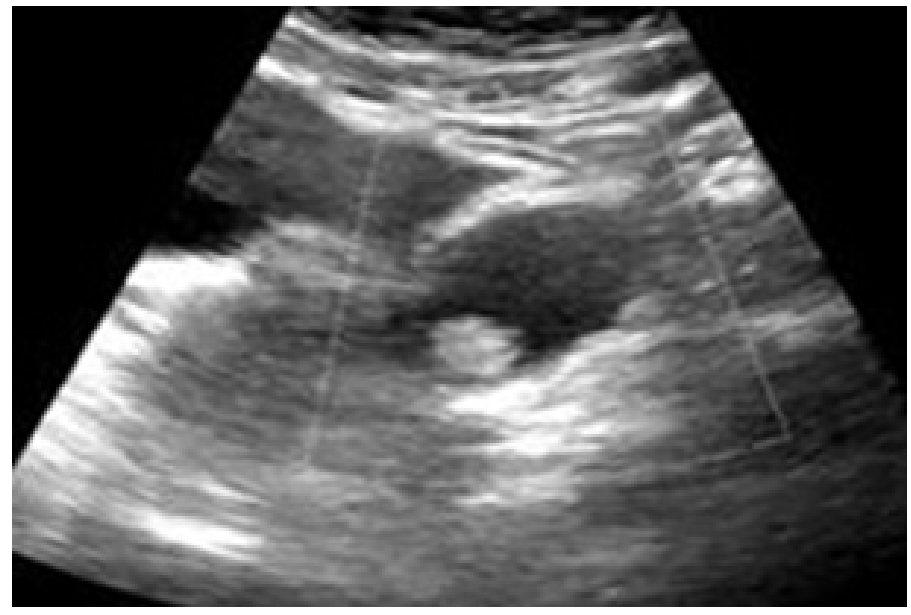

Fig. 4: Mature teratoma

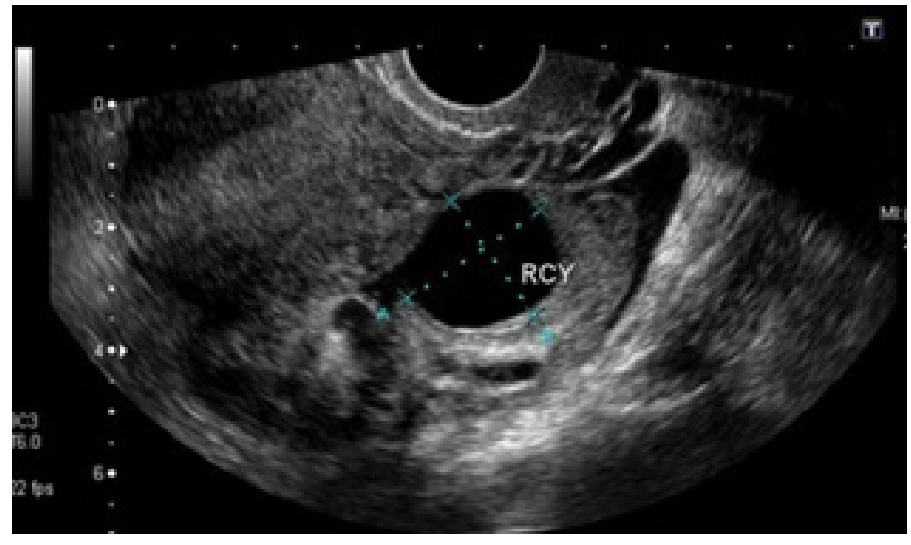

Fig. 5: Corpus luteum cyst 
TABLE 2: DIAGNOSIS TIME AND TREATMENT METHOD OF PREGNANCY COMPLICATED WITH OVARIAN TUMOR [n (\%)]

\begin{tabular}{lccccc}
\hline $\begin{array}{l}\text { Tumor diagnosis } \\
\text { time }\end{array}$ & Case number & $\begin{array}{c}\text { Non-surgical } \\
\text { treatment }\end{array}$ & Elective surgery & Emergency surgery & $\begin{array}{c}\text { Giving up } \\
\text { pregnancy }\end{array}$ \\
\hline Pre-pregnancy & 24 & 12 & 5 & 0 & 6 \\
Early pregnancy & 40 & 8 & 9 & 14 & 13 \\
Middle pregnancy & 22 & 14 & 11 & 4 & 0 \\
Late pregnancy & 74 & 56 & 0 & 8 & 0 \\
Total & 160 & 90 & 25 & 26 & 19 \\
\hline
\end{tabular}

TABLE 3: COMPARISON OF PREGNANCY OUTCOMES OF DIFFERENT TREATMENTS [n (\%)]

\begin{tabular}{|c|c|c|c|c|c|c|c|c|}
\hline \multirow{2}{*}{$\begin{array}{l}\text { Tumor } \\
\text { diagnosis } \\
\text { time }\end{array}$} & \multicolumn{3}{|c|}{ Surgical treatment } & \multicolumn{3}{|c|}{ Non-surgical treatment } & \multirow{2}{*}{$\begin{array}{c}\text { Giving up } \\
\text { pregnancy }\end{array}$} & \multirow[t]{2}{*}{ total } \\
\hline & $\begin{array}{c}\text { Case } \\
\text { number }\end{array}$ & $\begin{array}{c}\text { Premature } \\
\text { birth }\end{array}$ & Miscarriage & $\begin{array}{c}\text { Case } \\
\text { number }\end{array}$ & $\begin{array}{c}\text { Premature } \\
\text { birth }\end{array}$ & Miscarriage & & \\
\hline $\begin{array}{l}\text { Pre- } \\
\text { pregnancy }\end{array}$ & 5 & 0 & 0 & 12 & 0 & 0 & 6 & 23 \\
\hline $\begin{array}{l}\text { Early } \\
\text { pregnancy }\end{array}$ & 23 & 0 & 0 & 8 & 2 & 0 & 13 & 44 \\
\hline $\begin{array}{l}\text { Middle } \\
\text { pregnancy }\end{array}$ & 15 & 0 & 0 & 14 & 2 & 0 & 0 & 29 \\
\hline $\begin{array}{l}\text { Late } \\
\text { pregnancy }\end{array}$ & 8 & 3 & 0 & 56 & 0 & 0 & 0 & 64 \\
\hline Total & $51(31.88)$ & $3(5.88)$ & $0(0.00)$ & $90(56.25)$ & $4(4.44)$ & $0(0.00)$ & $19(11.88)$ & $160(100.00)$ \\
\hline
\end{tabular}

\section{Author's contributions:}

These authors contributed equally to this work.

\section{Conflicts of interest:}

The authors declared no conflict of interest.

\section{REFERENCES}

1. Li WJ, Yue GH, Su GJ, Kong LF, Zhang SL. The influence of the treatment of complicated ovarian tumors during pregnancy on the outcome of pregnancy. Chin J Clin Ration Drug Use 2014; 12(31):133-4.

2. Tang L, Wei L, Ye JM. Clinical analysis and pregnancy outcome of 105 patients with ovarian tumor during pregnancy. Guide China Med 2014;23(30):52-3.

3. Cheng L, You X, Wang G. Clinical characteristics and management of ovarian tumor during pregnancy. J Baotou Med Coll 2014;14(2):41-4.

4. Yu YX, Li J, Chen H, Ren W, Qu DY, Chen J. Treatment of pregnancy complicated with ovarian tumor and its impact on pregnancy outcome. Med Pharma J Chin PLA 2013;22(2):2458.

5. Yu YX, Li J, Chen H, Chen J, Wang L. Effect of pregnancy with ovarian tumor or ovarian tumor-like lesions on pregnancy outcome. J Chin Peop Armed Poli Forc 2012;(11):14-6.

6. Shang L, Wang Y, Lyu Y. Clinical effect of mifepristone on patients with ovarian cancer in pregnancy. Pakistan J Pharm Sci 2019;32(1):421-6.

7. Chao AS, Chang SD, Wang CJ, Chao A, Wang TH. Abscess formation in ovarian endometriomas after failure of mifepristone-induced abortion. Clin Exp Obstet Gynecol 2016;43:766-8.
8. Fu Z, Kelley JL, Odunsi K, Edwards RP, Moysich K, Modugno F. Gestational weight gain and risk of epithelial ovarian cancer. Cancer Causes Control 2021:1-9.

9. Gaba F, Robbani S, Singh N, McCluggage WG, Wilkinson $\mathrm{N}$, Ganesan R, et al. Preventing ovarian cancer through early excision of tubes and late ovarian removal (Protector): protocol for a prospective non-randomised multi-center trial. Int J Gynecol Cancer 2021;31(2):286-91.

10. Howitt BE, Hanamornroongruang S, Lin DI, Conner JE, Schulte S, Horowitz N, et al. Evidence for a dualistic model of high-grade serous carcinoma: BRCA mutation status, histology and tubal intraepithelial carcinoma. Am J Surg Pathol 2015;39(3):287-93.

11. Eckert MA, Pan S, Hernandez KM, Loth RM, Andrade $\mathrm{J}$, Volchenboum SL, et al. Genomics of ovarian cancer progression reveals diverse metastatic trajectories including intraepithelial metastasis to the fallopian tube. Cancer Discov 2016;6(12):1342-51.

12. Ahmed AA, Etemadmoghadam D, Temple J, Lynch AG, Riad M, Sharma R, et al. Driver mutations in TP53 are ubiquitous in high grade serous carcinoma of the ovary. J Pathol 2010;221(1):49-56.

This is an open access article distributed under the terms of the Creative Commons Attribution-NonCommercial-ShareAlike 3.0 License, which allows others to remix, tweak, and build upon the work non-commercially, as long as the author is credited and the new creations are licensed under the identical terms

This article was originally published in a special issue,

"Therapeutic Perspectives in Biomedical Research and Pharmaceutical Sciences and their Nursing Methods"

Indian J Pharm Sci 2021:83(4)Spl issue "153-157" 